\title{
Verification of Archie Constants Using Special Core Analysis and Resistivity Porosity Cross Plot Using Picket Plot Method
}

\author{
Said M. Edbieb ${ }^{1}$, Mohamed S. Nasr ${ }^{2}$, Abdulrrazzg Y. Zekri ${ }^{3}$
}

\begin{abstract}
The static and dynamic vertical distribution of fluids in the reservoir is the basis for:

1) Estimation oil initially in place

2) Determination of the thickness of the perforated interval in the producing formation

3) Controlling the production performance from the reservoir
\end{abstract} The calculation of the vertical fluids saturation distribution using Archie equation or capillary pressure technique is very sensitive when it used for either the calculation of oil in place or monitoring future reservoir performance for the purpose of determining the expected recovery factor for each well or the reservoir as whole. It is therefore necessary to verify the data obtained from each method and investigate the difference before using in the previous mentioned applications. The Archie equation is one of the powerful tools for determining the static vertical fluids saturation distribution in the reservoir. Archie constants which are the saturation exponent, the cementation factor and the tortuosity constant are obtained from two methods, special core analysis experiments or from porosity resistivity cross plots obtained form well log analysis.

The vertical static fluids saturation distribution in cored wells can easily be determined with Archie equation using Archie constants obtained from special core analysis experiments run on cores collected from selected wells in the reservoir. In reservoir simulation studies for the purpose of either the calculation of oil in place or the prediction of the future behavior of the reservoir, it is important to determine the saturation profile for each part of the reservoir. The parts of the reservoir that have no core analysis data the saturation profile cannot be determined. It is therefore necessary to find a method to determine this profile for none cored wells in the reservoir.

The cross plot of the resistivity versus porosity method (Picket plot) can be constructed for each logged well, which can be used to determine the Archie constants in the logged well using special techniques. Once the Archie constants from both methods, the special core analysis technique and the Picket plot resistivity versus porosity technique are verified with each other, then the representative constants are populated for all the parts of the reservoir using the calculated porosity profile obtained porosity contour maps. The objective of this study to:

1) Determine the Archie constants from two methods: Special core analysis from cored wells.

- Resistivity porosity cross plot technique from logs for the same cored wells.

2) Verification of the Archie constants from both methods and determine the representative values to be used for the whole reservoir

This study is conducted using the special core analysis data and well $\log$ data for four oil wells from a sandstone reservoir in Sirte

\footnotetext{
${ }^{1,2}$ Professor of Petroleum Engineering, Department of Petroleum Engineering / University of Tripoli, Libya

${ }^{3}$ Professor of Petroleum Engineering, Department of Petroleum Engineering / University of United Arab Emirates UAE.
}

basin Libya. The formation resistivity factor and the saturation index constants obtained from laboratory experiments and the same constants obtained from the porosity resistivity cross plot (Picket plot) were used in the calculation of the vertical fluids saturation distribution profile for the reservoir using Archie equation.

This study is conducted using the special core analysis data and well $\log$ data for four oil wells from a sandstone reservoir in Sirte basin Libya. The formation resistivity factor and the saturation index constants obtained from laboratory experiments and the same constants obtained from the porosity resistivity cross plot (Picket plot) were used in the calculation of the vertical fluids saturation distribution profile for the reservoir using Archie equation.

The results of this study indicated that the values of the Archie constant obtained from the special core analysis experiments are used to select the suitable technique for determining the Archie constant form the resistivity porosity cross plots. Once the selection method has been found for the cored and logged wells then it then was generalized for other logged wells in the reservoir. It is concluded that this method of populating the Archie constant in parts of the reservoir where there is no core wells will give valuable information to reservoir simulation studies.

Keywords - Archie Constants, Core Analysis, Picket Plot Method

\section{INTRODUCTION}

\section{Formation resistivity factor}

$\mathrm{T}$ $\mathrm{HE}$ formation resistivity factor is a function of the type and character of formation and varies with other properties such as the porosity and permeability of the reservoir rock. It is related to the porosity, $\phi$, of rock through the following general relationship ${ }^{1,2}$.

$$
F=a / \phi^{\wedge} m
$$

Where (a) and (m) are constants varying considerably depending on the rock type. This relation is essential if the step from an electrical parameter to a rock parameter is to be made. Its practical application is accomplished by evaluating the constants (a) and (m) using laboratory measured values of (F) and $(\phi)^{3,4}$. The most commonly used formulae are:

Archie's formula:

$$
F=\frac{1}{\phi^{2}}
$$

Humble formula:

$$
F=\frac{0.62}{\phi^{2.15}}
$$

Formation Resistivity Factor (FF or FR)

An important relationship exists between the resistivity of a fully water saturated formation and the resistivity of the 
contained water. The ratio of these two values is called Formation Resistivity Factor. The most fundamental concept in considering electrical properties of rocks is that of formation Resistivity factor FF is a constant for the formation under consideration. It is defined as the ratio of the resistivity of the rock when completely saturating brine. It is an important term incorporated with the determination of hydrocarbon saturation, by Archie $1941^{1,5}$.

Where:

$$
\mathrm{FF}=\frac{\mathrm{Ro}}{\mathrm{Rw}}
$$
ת.m.

$R_{0}=$ Resistivity of a Rock $100 \%$ Saturated with water,

$$
\mathrm{R}_{\mathrm{w}}=\text { Resistivity of the water, } \Omega . \mathrm{m}
$$

\section{Resistivity of the Formation}

Is defined as the resistance offered by a formation to the flow of electrical current. It is expressed in ohm-metre ${ }^{2} /$ meter and it is denoted by the term $R_{t}$ which describes the resistivity of a formation undisturbed by the drilling process where $R_{0}$ describes a special form of $\mathrm{R}_{\mathrm{t}}$. It is the resistivity of a clean formation when all pore space is filled with connate water $\left(\mathrm{R}_{\mathrm{w}}\right)$. The resistivity of a formation is a key parameter in determining hydrocarbon saturation ${ }^{6}$

The conductivity of sedimentary rocks is produced by the movement of ions in the formation water. Since rock conduction is essentially electrolytic in nature, the well logs measuring resistivity can be considered to be salt water indicators. Formation resistivity's are usually from 0.2 to1000 ohm-m. Resistivities higher than $1000 \mathrm{Ohm}-\mathrm{m}$ are uncommon in permeable formations but are observed in impervious, very low porosity formations (e.g. evaporates).

$$
\text { Resistivity }=\frac{1}{\text { Conductivity }} \text {. }
$$

\section{Formation water resistivity, $R_{w}$}

As previously indicated, formation matrices are insulators; thus a formation's ability to conduct electricity is a function of the connate water saturation and salinity in the formation. The formation water resistivity $\left(\mathrm{R}_{\mathrm{w}}\right)$ can be determined from SP and or porosity resistivity cross plot (Picket Plot) or from the composition of the formation water ${ }^{7,8}$.

\section{Well logging measurements}

The log measurements generally include electrical, acoustic, and nuclear properties of the surrounding medium and it also includes the combined properties of both the rock matrix and the fluids in the pore space. The resulting records of measured properties versus depth are variously referred to as wire line logs, well logs, geophysical logs, or just plain logs. These logs give indirect information regarding the distribution of the critical reservoir properties discussed above. In this study a complete package of porosity and resistivity logs, including neutron, density, sonic and induction logs, have been recorded across the reservoir. Interval of each log was read every half foot and analyzed in detail for porosity, volume of shale, electrical properties of the rock, water saturation, and net pay thickness. Shale volume can be determined using gamma ray $\log$ or SP $\operatorname{logs}$ and Neutron-density crosses plot. In this study only the gamma Ray logs were used to determine the shale contents for the field ${ }^{9,10}$

\section{Determination of Water Saturation ( $S w)$ :}

All available measurements performed on reservoir samples and in wells, such as core analysis and well $\operatorname{logs}$, are extensively used in evaluating water saturation $\left(S_{w}\right)$. Combining the two original Archie equations together and rearranging to solve for water saturation, $S_{\mathrm{W}}$ gives ${ }^{11,12}$.

$$
S \boldsymbol{w}=\left[\frac{a x R \boldsymbol{w}}{\phi^{m} x R t}\right]^{\frac{1}{n}}
$$

\section{RESULTS AND DISCUSSION}

The following figures (1 and 2) are showing the distribution of porosity and permeability with depth for the wells (A62 and A72) respectively. The data for these two curves were obtained from routine core analysis experiments run on core samples from the two wells. It is concluded from the two figures that the reservoir zonation consists of five distinct producing layers. Figures 3 and 4 shows the cross plots of horizontal and the vertical permeabilities for the wells A62 and $\mathrm{A} 72$ respectively. It noticed from the two figures that the reservoir rock is homogeneous since the permeability values for both wells lie in both sides of the $45^{0}$ degree line. It is therefore concluded that the core samples collected from the wells are representative for the entire producing formation.

\section{Calculation of Formation Resistivity factor $(F F)$}

The formation resistivity factor is determined by running special core analysis experiments on core samples collected from the producing formation. The cementation factor $(\mathrm{m})$ is an essential parameter in the Archie Formula to determine resistivity formation factor (FF) and then water saturation. This parameter can be obtained from special core analysis available, and it can be determined using the relationship between (FF) and $(\phi)$. In this study, curve was constructed by plotting porosity $(\phi)$ values versus resistivity formation factor (F) values of 2 wells on log-log paper, and fit the calculated values to a straight line, the intercept will give the value "a", and the slope is the cementation factor $(\mathrm{m})$. The following figures (5 and 6) are showing the relationship between (FF) and $(\phi)$ for the wells (A62 and A72) respectively.

Resistivity Index is the ratio of the rock resistivity when it is partially saturated with water to its resistivity when it is $100 \%$ saturated with water. Special core analysis experiments were run on core samples collected from wells A62 and A72 for the determination of the saturation exponent (n). The following figures (7 and 8) shows the data obtained from these experiments. The Archie constants were obtained experimentally from the core samples which represent the five formation layers in the two cored and wells A62 and A72. 

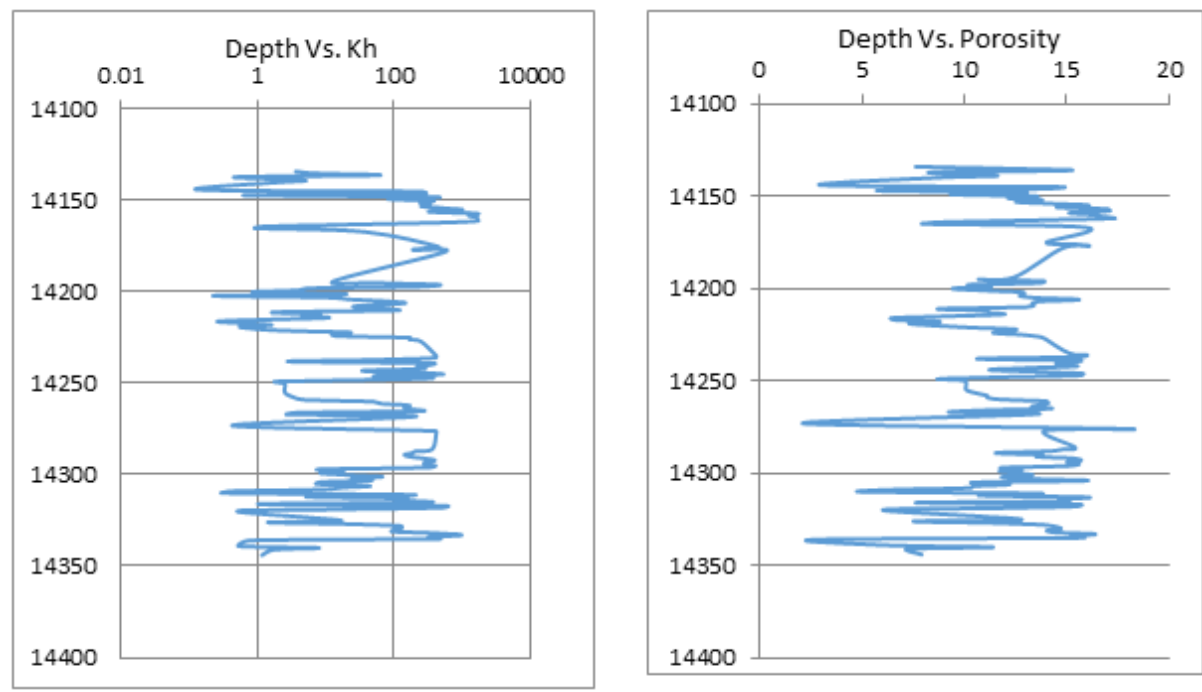

Fig 1 Shows the distribution of porosity and permeability with depth using routine core analysis data for well A 62
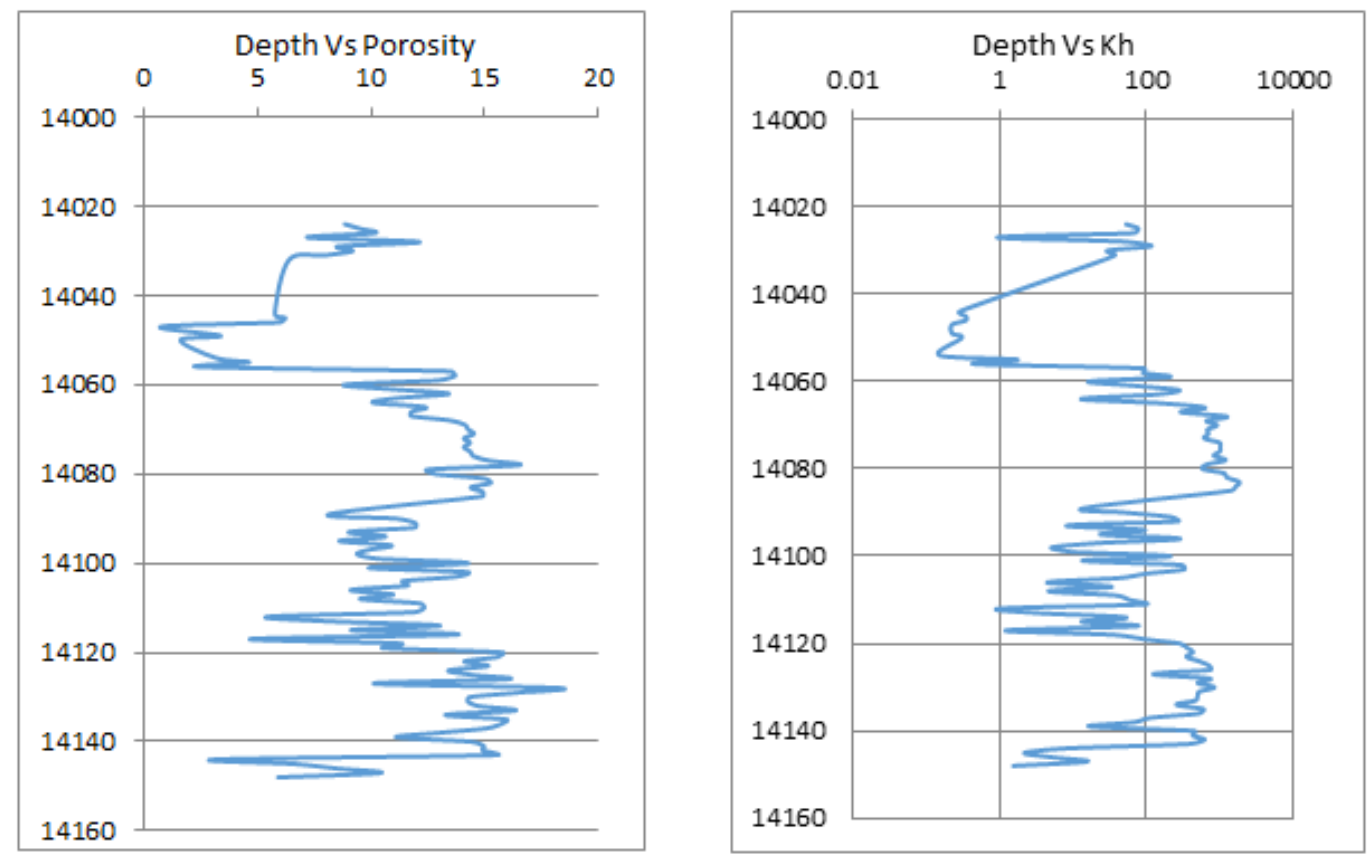

Fig 2 shows the distribution of porosity and permeability with depth using routine core analysis data for well A 72.

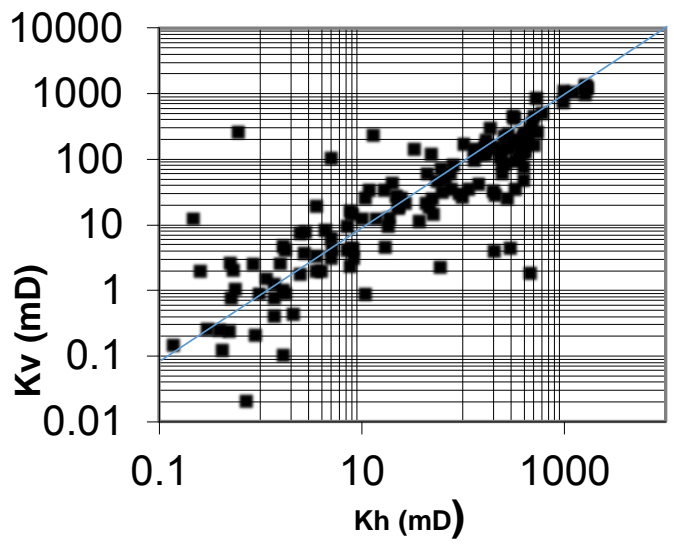

Fig. 3 Shows horizontal versus vertical permeability for well A-62

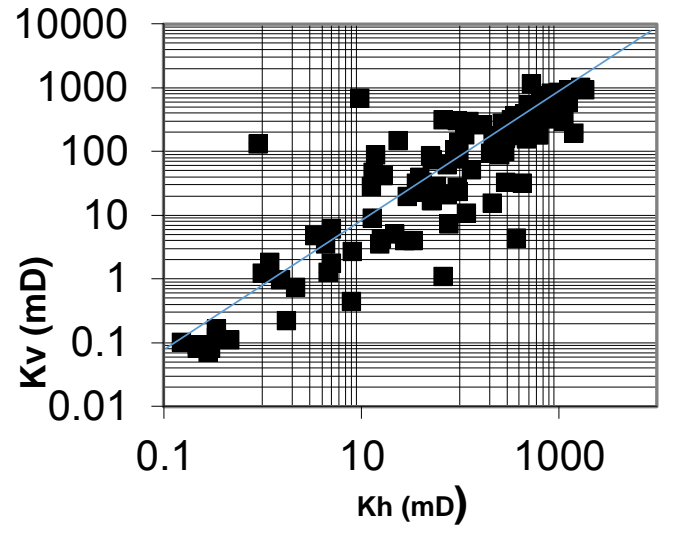

Fig. 4 Shows horizontal versus vertical permeability for well A-72 


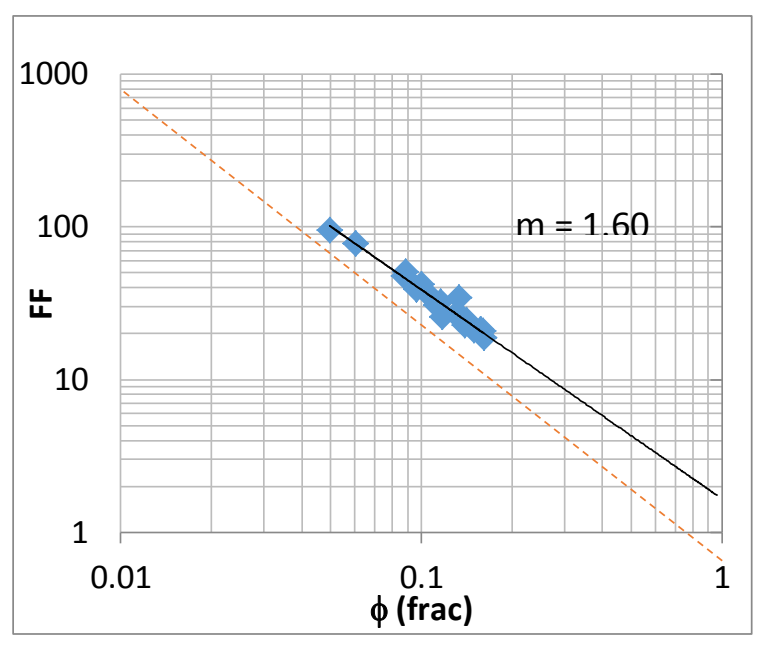

Fig 5 Shows log-log plot of FF versus $\phi$ for well A62

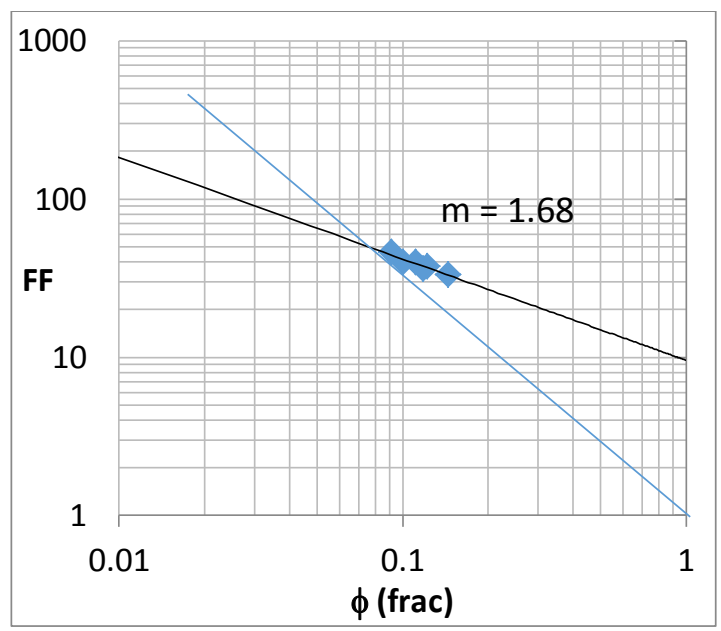

Fig 6 Shows log-log plot of FF versus $\phi$ for well A72

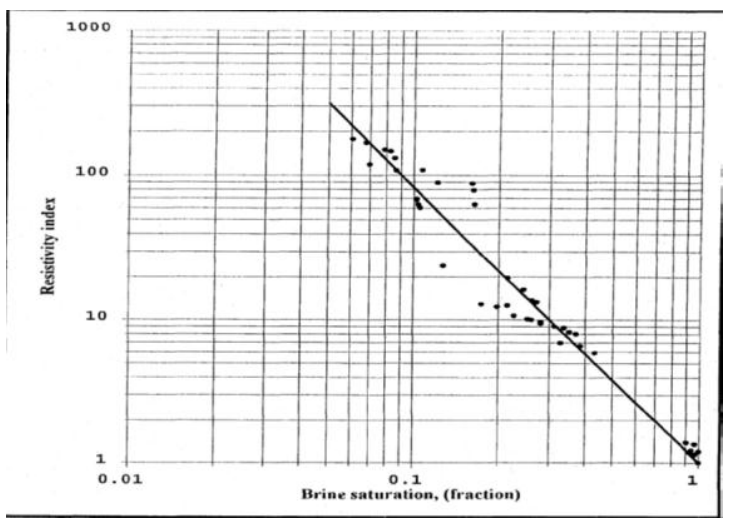

Fig 7 Shows log-log plot of the resistivity index (RI) versus water saturation $(\mathrm{Sw})$ for well A-62

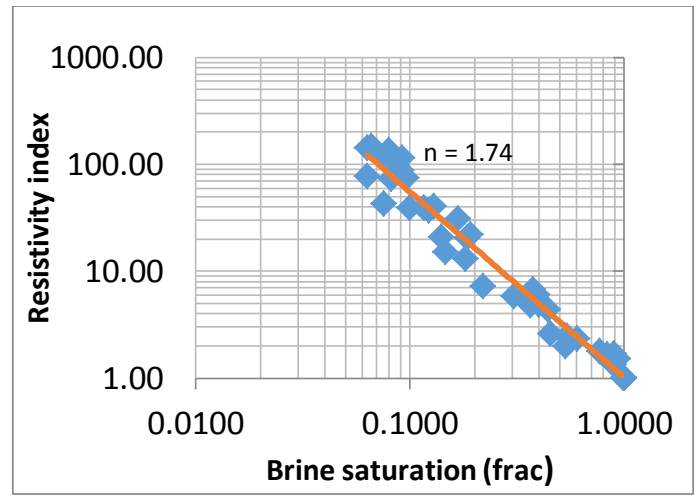

Fig 8 Shows log-log plot of the resistivity index (RI) versus water saturation $(\mathrm{Sw})$ for well A-72

The following table (1) illustrate the Archie constant obtained from special core analysis experiments run on core samples collected from wells A62 and A72 in the field. The results in the table will be compared with the results obtained from the cross plot of porosity versus resistivity for the same wells.

TABLE I

SHOWS THE ARCHIE CONSTANTS OBTAINED FROM THE SPECIAL CORE ANALYSIS RESULTS FOR WELLS A62 AND A72

\begin{tabular}{|c|c|c|c|}
\hline Well No. & $\begin{array}{l}\text { Cementation } \\
\text { Factor }(\mathrm{m})\end{array}$ & $\begin{array}{l}\text { Saturation } \\
\text { Exponent (n) }\end{array}$ & $\begin{array}{l}\text { Tortuosity } \\
\text { (a) }\end{array}$ \\
\hline A62 & 1.68 & 1.92 & 1 \\
\hline A72 & 1.60 & 1.74 & 1 \\
\hline
\end{tabular}

The electrical logs for the two wells A62 and A72 which include the gamma ray, the resistivity and the porosity logs for the producing interval confirm the existence of five producing layers in this reservoir. The results of the logs again confirm the same zonation number and order obtained from the porosity and vertical permeability measured from the routine core analysis experiments.

In this study, Pickett cross-plot was constructed by plotting porosity $(\phi)$ values versus true resistivity $\left(R_{t}\right)$ values of two wells A62 and A72 on log-log paper. A line of wet resistivity at $100 \% \mathrm{Sw}$ was drawn through the most south-west data points and the slope of this line represent the " $\mathrm{m}$ " value, the intercept will give the value " $\mathrm{aR}_{\mathrm{w}}$ ". The following figures (9 and 10) are showing the relationship between (Rt) and $(\phi)$ obtained from log data for the wells (A62 and A72) respectively.

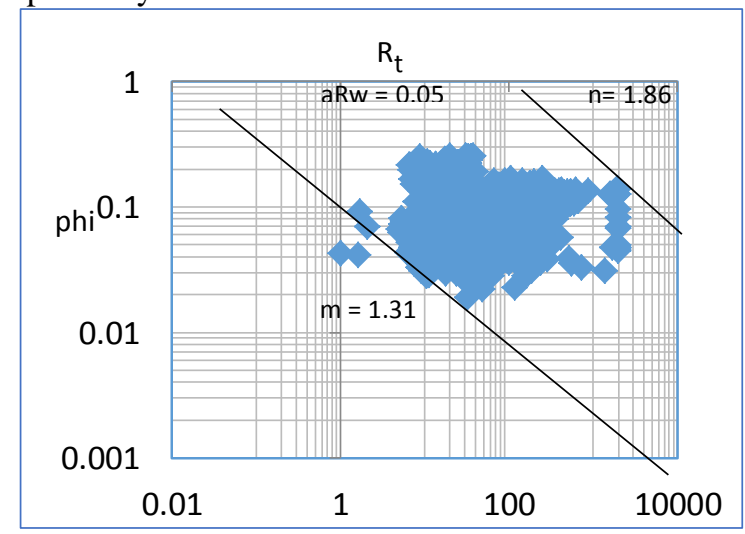

Fig 9 (Picket plot) Shows log-log plot of formation resistivity factor versus porosity for well A-62 


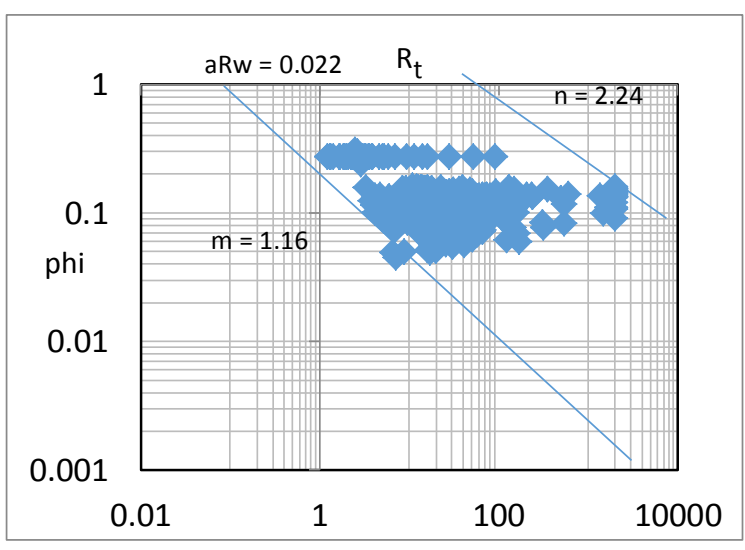

Fig 10 (Picket plot) Shows log-log plot of formation resistivity factor versus porosity for well A-72

The following table (2) illustrate the Archie constant obtained from porosity versus resistivity (Picket cross plot) for wells A62 and A72. The data is obtained from well log analysis for both wells. The Archie constants obtained from both wells are quite different from each other and this is due to the compaction trend of the reservoir layers which are divided by natural fractures and faults.

TABLE II

SHOWS THE ARCHIE CONSTANTS OBTAINED FOR THE PICKET CROSS PLOT OF POROSITY VERSUS RESISTIVITY FOR WELL A62 AND A72

\begin{tabular}{|c|c|c|c|}
\hline $\begin{array}{l}\text { Well } \\
\text { No. }\end{array}$ & $\begin{array}{l}\text { Cementation } \\
\text { Factor }(\mathrm{m})\end{array}$ & $\begin{array}{l}\text { Saturation } \\
\text { Exponent (n) }\end{array}$ & $\begin{array}{l}\text { Tortuosity } \\
\text { (a) }\end{array}$ \\
\hline A62 & 1.31 & 1.86 & 1.25 \\
\hline A72 & 1.16 & 2.24 & 0.55 \\
\hline
\end{tabular}

\section{CONCLUSION}

1. It is concluded that the values for Archie constants should be obtained for each zone in the reservoir and hence the water saturation versus depth distribution should be determined for each zone alone. The average for these parameters should not be done because averaging them for the whole reservoir will give great error in calculating the saturation distribution in the reservoir.

2. The Archie constants obtained experimentally from special core analysis show moderate different results compared to the same values obtained from the log data of the porosity resistivity cross plot (Picket Plot).

3. The Archie constants obtained from the laboratory experiments are very sensitive to the technique used for their calculations, therefore it is recommended that enough data points should be obtained using large amount of core samples in order to eliminate the error encountered in selected the best fit line for these data points.

4. It believed that the values of the Archie constant obtained experimentally are effected to a large extent by the unconsolidation nature of the reservoir rock since it is classified to be unconsolidated sandstone reservoir.

5. The Picket plot method for determining the Archie constants should be used together with the same values obtained from the special core results for populating the
Archie constants to areas of the reservoir where there are no cored wells in those areas.

\section{REFERENCES}

[1] Archie, G. E., the Electrical Resistivity Log as an Aid in Determining Some Reservoir Characteristics. Trans AIME, 1942. 146: PP. 54 - 67.

[2] Winsauer, H. M., Resistivity of Brine-Saturated Sands in Relation to Pore Geometry. AAPG Bulletin, 1952. 36 (2): PP. 253-277.

[3] Carothers, J. W., A Statistical Study of Formation Factor Relationship. The Log Analyst, 1968 (Sept. - Oct.): PP. $14-20$

[4] Schlumberger, Log Interpretation Principales and Applications, (1989).

[5] Awosika, A. O., Niger Delta Temperature and Porosity Studies, Petroleum Engineering Post graduate Degree Thesis, Department of Petroleum Engineering, University of Ibadan, 1992.

[6] Calhoun, J. R., Fundamentals of Reservoir Engineering. University of Oklahoma Press, 1976.

[7] Donald P. Helander, 1983 "Fundamental of Formation Evaluation" PP (99-111) - (178 181).

[8] Asquith, G. and Krygwski, D. (2004): Basic well log analysis" The American Association of Petroleum Geologists, Tulsa, Oklahoma.

[9] Bertozzi, W., Ellis, D.V., and Wahl, I. S., The Physical Foundations of Formation Lithology Logging with Gamma Rays Submitted to Geophysics.

[10] Best, D. L., Gardner, J .S. and Dumanoir, J. L., 1978, A ComputerProcessed Wellsite Log Computation, SPWLA 19th Annual Symposium Transactions.

[11] Calhoun, J. R., Fundamentals of Reservoir engineering. University of Oklahoma press, 1976.

[12] Hunt, E, Aly, A. \& Pursel, D, 1996, "Fundamentals of Log Analysis, part 8: Determining Porosity from Density, Neutron \& Acoustic Log, (173-176). World Oil, Vol. 128, No 7, Gulf Publishing Co. 